\title{
CONSERVAČ̃̃O PÓS-COLHEITA DE ESPIGAS DE MILHO VERDE MINIMAMENTE PROCESSADO SOB DIFERENTES TEMPERATURAS
}

\author{
Post-harvest conservation of fresh-cut corn on the cob (Zea maiz L.) \\ under different temperatures
}

\author{
Alexandra Mara Goulart Nunes Mamede², Adimilson Bosco Chitarra ${ }^{3}$, Marcos José de Oliveira Fonseca ${ }^{4}$, \\ Antonio Gomes Soares ${ }^{5}$, José Carlos Sá Ferreira ${ }^{5}$, Luiz Carlos de Oliveira Lima ${ }^{6}$
}

\begin{abstract}
RESUMO
Objetivou-se, neste trabalho, avaliar o efeito de três temperaturas $\left(5^{\circ} \mathrm{C}, 8^{\circ} \mathrm{C}\right.$ e $\left.11^{\circ} \mathrm{C}\right)$, na qualidade de híbridos de milho verde (Zea maiz L.) com endosperma normal, minimamente processado, durante oito dias de armazenamento, com avaliações a cada dois dias. Foram utilizadas espigas de dois híbridos, sendo um comercial da Sementes Agroceres (Ag 1051) e outro do programa de melhoramento da Embrapa Milho e Sorgo (Embrapa HT1). A temperatura de $5^{\circ} \mathrm{C}$ foi a que melhor preservou a qualidade das espigas dos híbridos de milho verde estudados, por proporcionar perda de massa reduzida e manutenção dos teores de sólidos solúveis, frutose e glicose. O híbrido Ag 1051 apresentou menor perda de massa, maiores valores de umidade e maior teor de frutose. O Embrapa HT1 apresentou maiores valores iniciais e finais para os teores de sólidos solúveis e maior valor para a coloração b*. O valor $\mathrm{L}^{*}$, que indica quãoclaro e escuro é produto, também diminuiu ao longo do armazenamento, indicando escurecimento das espigas ao longo do armazenamento.
\end{abstract}

Termos para indexação: Zea maiz, refrigeração, qualidade, glicose, frutose, vida útil.

\begin{abstract}
This work had the aim of evaluating the effect of three temperatures $\left(5^{\circ} \mathrm{C}, 8^{\circ} \mathrm{C}\right.$ and $\left.11^{\circ} \mathrm{C}\right)$ on the quality of fresh-cut corn on the cob (Zea maiz L.) with normal endosperm, for 8 days, with analyses taken every two days. Corn on the cob of two hybrids was used, a commercial common type from Sementes Agroceres (Ag 1051) and the other from the breeding program Embrapa Milho e Sorgo (Embrapa HT1). The temperature of $5^{\circ} \mathrm{C}$ was more efficient to preserve the quality of normal corn by promoting reduced mass loss and higher contents of soluble solids, fructose and glucose. The hybrid Ag 1051 presented lower mass loss, higher contents of moisture and higher content of fructose. The hybrid Embrapa HT1 presented higher initial and final values for soluble solids and higher $b^{*}$ value. The $\mathrm{L}^{*}$ value also decreased along storage, indicating browning of the corns along the storage.
\end{abstract}

Index terms: Zea maiz, refrigeration, quality, glucose, fructose, shelf-life

(Recebido em 29 de maio de 2007 e aprovado em 19 de março de 2008)

\section{INTRODUÇÃO}

Produtos minimamente processados podem ser definidos como frutas ou hortaliças, ou a combinação dessas que tenham sido fisicamente alteradas mas que permaneçam em estado fresco (CHITARRA, 2000). O processamento mínimo inclui operações de seleção, lavagem, descascamento e corte, visando obter um produto conveniente para o preparo e consumo (BURNS, 1995).

O consumo do milho verde com endosperma normal é tradicional no Brasil. Esse tipo de milho possui maior teor de amido em sua composição, sendo consumido tanto in natura (cozido ou assado), como enlatado e processado em forma de pamonha, de curau, de suco, de bolo, de sorvete, entre outros produtos tradicionais, durante o ano todo (PEREIRA FILHO et al., 2003).

Espigas de milho verde, desempalhadas e embaladas estão sendo cada vez mais ofertadas no mercado, sem os cuidados necessários para a manutenção de características adequadas e higiene. Os procedimentos para ofertar um produto de alta qualidade, não estão sendo

\footnotetext{
'Trabalho é parte da dissertação de Mestrado em Ciência dos Alimentos realizada na Universidade Federal de Lavras - UFLA

'Engenheira de Alimentos, Mestre em Ciência dos Alimentos - Doutoranda em Ciência dos Alimentos do Instituto de Química/IQ - Depto de Bioquímica Universidade Federal do Rio de Janeiro/ UFRJ - Avenida Brig. Trompowsky, s/n, Centro de Tecnologia, Bloco A 528 - Cidade Universitária - Ilha do Fundão - 21949-900 - Rio de Janeiro, RJ - alexandramaram@globo.com

${ }^{3}$ Doutor, Professor Titular - Departamento de Ciência dos Alimentos/DCA - Universidade Federal de Lavras/UFLA - Cx. P. 3037 - $37200-000$ - Lavras, MG abchitarra@terra.com.br

${ }^{4}$ Pesquisador - Embrapa Agroindústria de Alimentos - Avenida das Américas, 29501 - 23020-470 - Rio de Janeiro, RJ - mfonseca@ctaa.embrapa.br ${ }^{5}$ Técnico de Nível Superior - Embrapa Agroindústria de Alimentos - Avenida das Américas, 29501 - 23020-470 - Guaratiba, RJ - agomes@ctaa.embrapa.br; zecarlos@ctaa.embrapa.br

${ }^{6}$ Doutor em Ciência dos Alimentos, Professor Adjunto - Departamento de Ciência dos Alimentos/DCA - Universidade Federal de Lavras/UFLA - Cx. P. 3037 -37200-000 - Lavras, MG - Icolima@ufla.br
}

Ciênc. agrotec., Lavras, v. 33, n. 1, p. 200-206, jan./fev., 2009 
observados (MARCOS et al., 1999). No momento, não existem recomendações sustentadas pela pesquisa para a comercialização pós-colheita desse produto com qualidade (PEREIRA FILHO et al., 2003).

Como produtos minimamente processados são mais perecíveis do que os que lhe deram origem, recomenda-se o armazenamento em temperaturas menores que aquelas utilizadas para produtos íntegros (SCHLIMME, 1995). O uso de refrigeração no armazenamento de produtos hortícolas é o mais importante e simples procedimento para retardar a deterioração pós-colheita, pelo retardo do crescimento da maioria dos microrganismos, diminuição da taxa respiratória, da transpiração e redução de atividades enzimáticas (LUENGO, 2001; NUNES \& EMOND, 2003). Embora a temperatura a $0^{\circ} \mathrm{C}$ seja desejável para alguns produtos, a maioria é armazenada a $5^{\circ} \mathrm{C}$ e, algumas vezes, sob temperaturas mais elevadas como $10^{\circ} \mathrm{C}$ (KADER, 2002).

Objetivou-se, no presente trabalho, avaliar o efeito de diferentes temperaturas na conservação de híbridos de milho verde (Zea maiz L.), do tipo normal minimamente processado.

\section{MATERIALE MÉTODOS}

Foram utilizadas espigas de dois híbridos triplos de milho verde do tipo normal, sendo um da Sementes Agroceres (Ag 1051) e outro do programa de melhoramento da Embrapa Milho e Sorgo (Embrapa HT1). Os milhos foram cultivados em campos experimentais da Embrapa Milho e Sorgo, Sete Lagoas, MG, em condições controladas de adubação e de manejo de pragas e doenças. A colheita foi realizada no dia 15 de fevereiro de 2006 e o milho foi colhido no ponto em que os grãos se apresentavam na fase leitosa, conhecido como "ponto de milho verde". As espigas empalhadas foram acondicionadas e transportadas, no dia seguinte, para a Embrapa Agroindústria de Alimentos, no Rio de Janeiro, RJ. O processamento mínimo das espigas de milho verde, foi realizado no dia seguinte à colheita, na sala de Processamento Mínimo da Planta Piloto de Pós-Colheita. Primeiramente, retiraram-se as palhas superficiais, para eliminação da sujeira que veio do campo, selecionando-se as espigas livres do ataque de lagartas. Posteriormente, realizou-se a pré-lavagem das espigas com água corrente, na área suja do processamento. Em seguida, em sala climatizada a $15 \pm 3^{\circ} \mathrm{C}$, realizou-se a sanificação das espigas, por imersão em água a $5^{\circ} \pm 2 \mathrm{C}$, contendo $200 \mathrm{mg} . \mathrm{L}^{-1}$ de cloro ativo, por 15 minutos. Em seguida, removeu-se o restante da palha e dos estigmas, cortaram-se as extremidades das espigas e drenou-se o excesso de água. Nessa etapa, promoveu-se nova seleção retirando-se aquelas mal granadas e as atacadas por lagartas não detectadas anteriormente.
As espigas foram acondicionados em bandejas de poliestireno $(23,5 \mathrm{~cm} \times 18,2 \mathrm{~cm})$, cada uma com duas unidades, sem recobrimento com filme plástico, para não ocorrer interferência da atmosfera modificada, gerada pelos filmes, nos resultados. O armazenamento foi feito em câmaras de refrigeração com umidade relativa (UR) de $90 \pm 5 \%$, em três temperaturas: $5 \pm 0,5^{\circ} \mathrm{C}, 8 \pm 0,5^{\circ} \mathrm{C}$ e $11 \pm 0,5^{\circ} \mathrm{C}$, por 8 dias. As bandejas foram armazenadas, aleatoriamente, no interior da câmara fria, com três repetições para cada híbrido. As espigas foram avaliadas no dia do processamento e após 2, 4, 6 e 8 dias de armazenamento, quanto à perda de massa, determinação instrumental da cor $\left(\mathbf{L}^{*}, \mathbf{b}^{*}\right)$, realizada por reflectância no S \& M Colour Computer modelo SM-4-CH da Suga, no sistema Hunter, com abertura de $13 \mathrm{~mm}$ de diâmetro e placa branca. As leituras foram feitas próximas às duas extremidades e na região central das mesmas espigas, ao longo do armazenamento. Textura dos grãos $(10 \mathrm{~g})$ após debulha das espigas: por compressão em texturômetro, modelo TA-Hdi, da Stable Micro System, com sonda Kramer Shear Cell HDP/K35 (velocidade do pré-teste: $2,00 \mathrm{~mm} \mathrm{~s}^{-1}$, velocidade de compressão de $2,00 \mathrm{~mm} . \mathrm{s}^{-1}$ e velocidade de retorno de $\left.10 \mathrm{~mm} \cdot \mathrm{s}^{-1}\right)$. Os resultados foram expressos em Newtons $(\mathrm{N})$. seguindo-se a metodologia de Paes et al. (2004), adaptada por Mamede et al. (2006a).

Após a trituração, em liquidificador, dos grãos de milho debulhados e filtragem, realizou-se a determinação dos teores sólidos solúveis (SS) com auxílio de refratômetro digital Atago PR-101. Os resultados foram expressos em ${ }^{\circ}$ Brix, de acordo com a ISO 2173 (ISO, 1978). A umidade foi determinada em estufa a $98^{\circ} \mathrm{C}-100^{\circ} \mathrm{C}$, segundo o método 934.01 da AOAC (2000). Os teores de glicose, frutose e sacarose foram determinados segundo Macrae (1998), por cromatografia líquida de alta eficiência. Aproximadamente, $1 \mathrm{~g}$ de amostra foi extraída com, aproximadamente, $10 \mathrm{~mL}$ de água Milli-Q em ultrasom, por 20 minutos. Logo após, adicionaram-se $5 \mathrm{~mL}$ de acetonitrila e o volume final foi ajustado para $25 \mathrm{~mL}$, com água Milli-Q. O extrato foi centrifugado e transferido diretamente para o frasco do injetor automático (vial), de onde $20 \mu \mathrm{L}$ foram injetados em cromatógrafo Waters Alliance 2695, com detetor de índice de refração Waters 2410, coluna Amino 4,6mm x 250mm (High Performance Carbohydrate), com temperatura $30^{\circ} \mathrm{C}$, fase móvel acetonitrila $75 \%$ em água Milli-Q, com fluxo de $1,3 \mathrm{~mL} / \mathrm{min}$.

O delineamento estatístico foi inteiramente casualizado, em parcelas subdivididas, com a temperatura na parcela e arranjo fatorial 2 x 5 nas subparcelas ( 2 híbridos e 5 tempos de armazenamento), com 3 repetições. A parcela experimental foi constituída por uma bandeja de poliestireno (isopor) contendo duas espigas de milho 
verde. As análises estatísticas foram realizadas com o auxílio do programa estatístico Sisvar (FERREIRA, 2000). Após a análise de variância, as médias dos fatores qualitativos foram comparadas utilizando-se teste $\mathrm{F}$ e ou Tukey, adotando-se probabilidade $5 \%$. Para o fator tempo de armazenamento, os modelos de regressões polinomiais foram selecionados, com base na significância do teste de F e pelo coeficiente de determinação.

\section{RESULTADOS E DISCUSSÃO}

Observou-se aumento da perda de massa ao longo do armazenamento para os dois híbridos de milho verde, sendo essa maior para o híbrido Embrapa HT1 (Figura 1).

Segundo Chitarra \& Chitarra (2005), o principal fator responsável pela perda de massa, durante o armazenamento de frutas e hortaliças, é a transpiração. Perdas na ordem de $3 \%$ a $6 \%$ são suficientes para causar marcante declínio na qualidade.

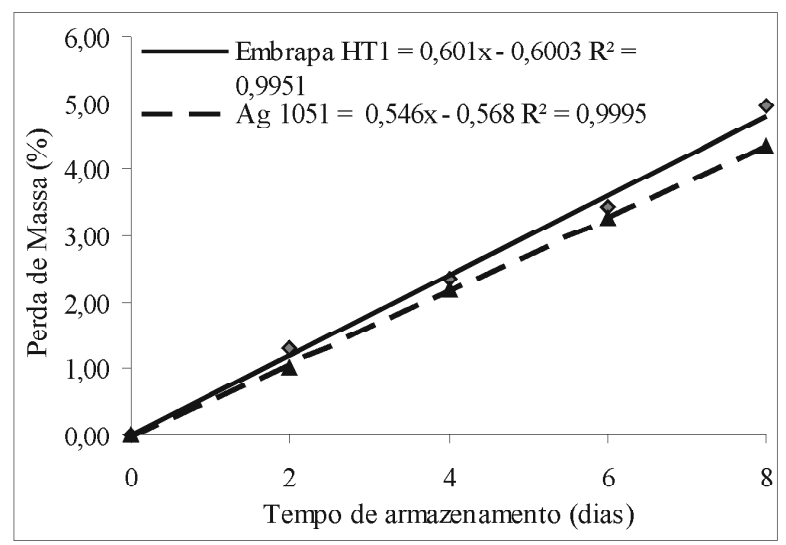

Figura 1 - Estimativa da perda porcentual de massa de milhos verdes 'Embrapa HT1' e 'Ag 1051' minimamente processados e armazenados, por 8 dias.

Considerando-se que perdas de massa, na ordem de $3 \%$ sejam suficientes para o declínio da qualidade das espigas de milho verde, pôde-se constatar que o híbrido Embrapa HT1 poderia ser comercializado até o $5^{\circ}$ dia de armazenamento e o Ag 1051 até \pm 6 dias.

Sabe-se que, quanto menor a temperatura de armazenamento, menor é a taxa respiratória, logo, menor será a transpiração e, conseqüentemente, menor a perda de massa. Em milhos verdes minimamente processados, as maiores perdas de massa foram encontradas no armazenamento a $11^{\circ} \mathrm{C}$ (Figura 2). Os valores de perda de massa, para as temperaturas de $5^{\circ} \mathrm{C}$ e $8^{\circ} \mathrm{C}$, não diferiram estatisticamente entre si. Considerando-se as perdas de massa na ordem de $3 \%$, a vida útil dos milhos verdes minimamente processados e armazenados a $11^{\circ} \mathrm{C}$ foi de \pm 4 dias, enquanto que, para as temperaturas de $5^{\circ} \mathrm{C}$ e $8^{\circ} \mathrm{C}$, a vida útil foi de \pm 6 dias, pois com 8 dias de armazenamento, as espigas apresentavam-se muito ressecadas, fato que determinou a interrupção do experimento.

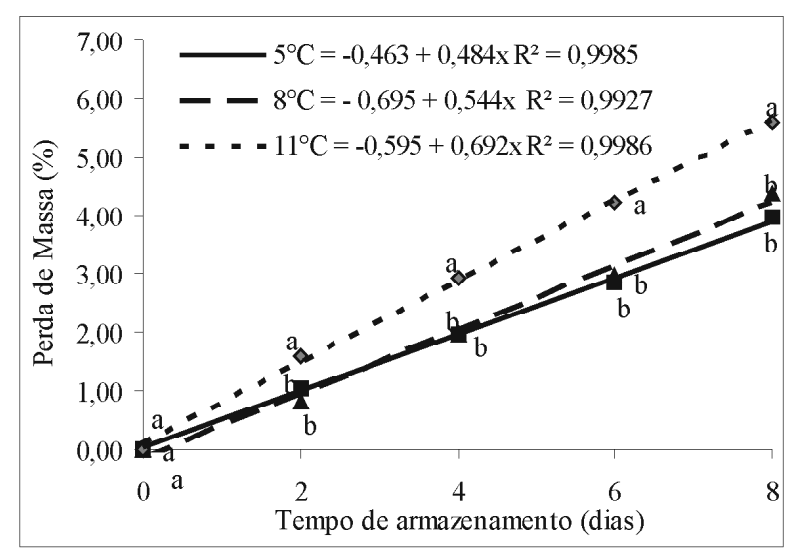

Figura 2 - Estimativa da perda porcentual de massa média dos híbridos de milho verde, minimamente processados armazenados em diferentes temperaturas $\left(5^{\circ} \mathrm{C}, 8^{\circ} \mathrm{C}\right.$ e $\left.11^{\circ} \mathrm{C}\right)$, por 8 dias.

*Médias seguidas da mesma letra, em cada tempo, não diferem entre si a $5 \%$ de probabilidade, pelo teste de Tukey.

A porcentagem de umidade foi significativamente maior no híbrido Ag 1051 que no Embrapa HT1, com média de $65,81 \%$ e $60,52 \%$ de umidade, respectivamente. Pôdese observar pela Figura 3, que ocorreram flutuações nas porcentagens de umidade, para os dois híbridos estudados, ao longo do armazenamento. Essas variações podem ser atribuídas à variabilidade entre as espigas de um mesmo híbrido, no momento da colheita. Fato semelhante foi observado em estudo feito por Camacho et al. (2001) com híbridos de milho doce armazenados a $4^{\circ} \mathrm{C}$, durante 28 dias.

O híbrido Embrapa HT1 apresentou valores médios de textura significativamente maiores que o Ag 1051, com $340,71 \mathrm{~N}$ e $298,06 \mathrm{~N}$, respectivamente. Para os híbridos de milho verde estudados, quanto maior a umidade dos grãos menor a textura. O híbrido Embrapa HT1 apresentou menores valores de umidade (Figura 3), de forma geral. Como o principal fator de perda de massa é a transpiração, quanto maior a perda de água nos grãos de milho, maior a perda de massa, aumentando, assim, a textura.

O teor de umidade tem relação direta com a textura, pois é um dos fatores responsáveis pelo turgor e pela textura do tecido (CHITARRA \& CHITARRA, 2005). De acordo com as equações de regressão da Figura 4, nos primeiros dias de armazenamento, a textura diminuiu, devido 
à perda de água dos grãos de milho, ocorrendo a diminuição do turgor celular e, conseqüentemente, o decréscimo nos valores de textura. A partir do $2^{\circ}$ dia de armazenamento, os valores de textura aumentaram, com leve decréscimo a partir do $6^{\circ}$ dia, com exceção do milho armazenado a $5^{\circ} \mathrm{C}$. O aumento observado pode ter ocorrido pela maior resistência ao rompimento das células, pois com a perda de água dos tecidos, ocorre um "emborrachamento" das células do grão de milho.

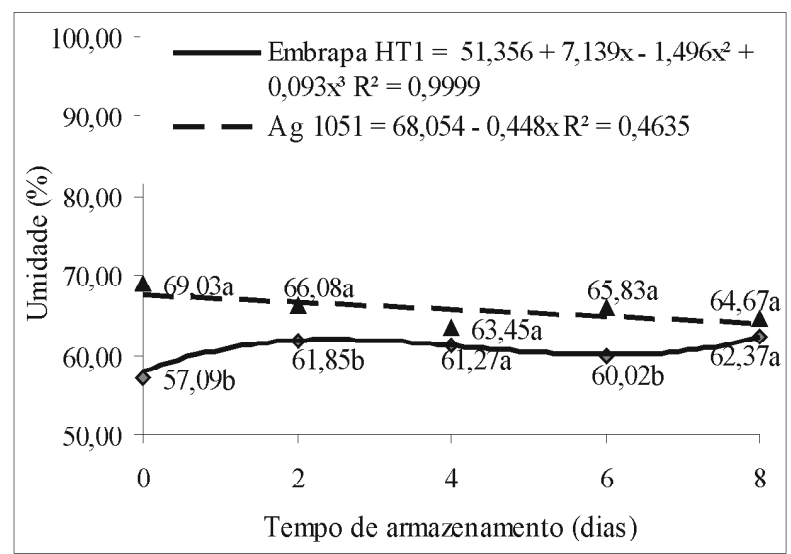

Figura 3 - Estimativa da umidade (\%) em milhos verdes 'Embrapa HT1' e 'Ag 1051' minimamente processados, armazenados sob refrigeração, por 8 dias.

*Médias seguidas da mesma letra, em cada tempo, não diferem entre si a 5\% de probabilidade, pelo teste de Tukey.

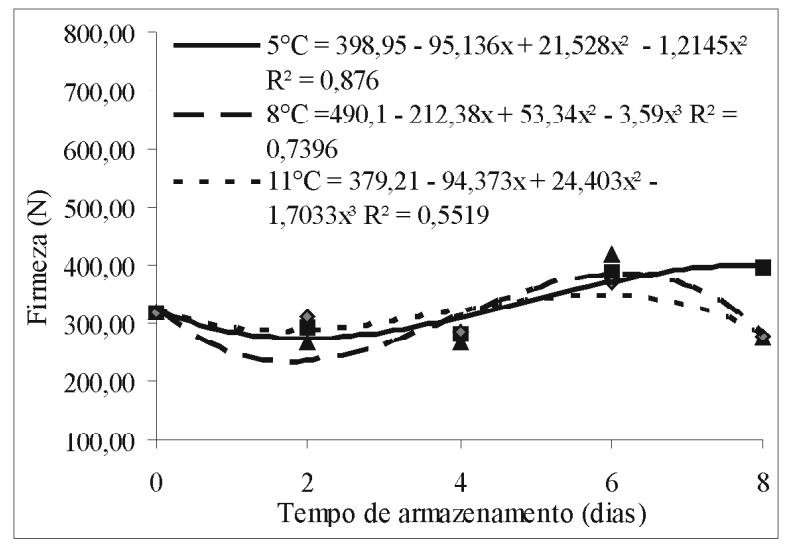

Figura 4 - Estimativa de textura $(\mathrm{N})$ média dos híbridos de milho verde minimamente processados, armazenados em diferentes temperaturas $\left(5^{\circ} \mathrm{C}, 8^{\circ} \mathrm{C}\right.$ e $\left.11^{\circ} \mathrm{C}\right)$, por 8 dias.

Os teores de SS foram significativamente maiores nas espigas armazenadas sob temperatura de $5^{\circ} \mathrm{C}$ $\left(10,95^{\circ}\right.$ Brix $)$, em relação a $8^{\circ} \mathrm{C}\left(10,35^{\circ}\right.$ Brix $)$ e $11^{\circ} \mathrm{C}\left(10,08^{\circ}\right.$ Brix $)$, que diferiram estatisticamente entre si. Para o híbrido Ag 1051, observou-se, ao longo do armazenamento, redução nos SS de 11,2\% para 9,4\% (Figura 5). Já o híbrido Embrapa HT1 apresentou oscilações nos SS ao longo do armazenamento, com valores inicial e final de $11,9 \%$ e 9,7\%, respectivamente. Zhu et al. (1992) encontraram redução nos SS de milho doce (16,8 para $15,8^{\circ}$ Brix) armazenado a $6^{\circ} \mathrm{C}$ por 5 dias, com oscilações semelhantes ao híbrido Embrapa HT1.

A sacarose não foi detectada nos híbridos de milho verde estudados, em nenhum dos tempos avaliados. De acordo com Luengo \& Calbo (2001), no milho verde armazenado a $21^{\circ} \mathrm{C}$, o teor de sacarose pode ser reduzido em mais de $30 \%$ por dia. Como a colheita foi feita num dia e o transporte e processamento mínimo no dia seguinte, a sacarose pode ter sido invertida em glicose e frutose e parte pode ter sido usada para a síntese de amido.

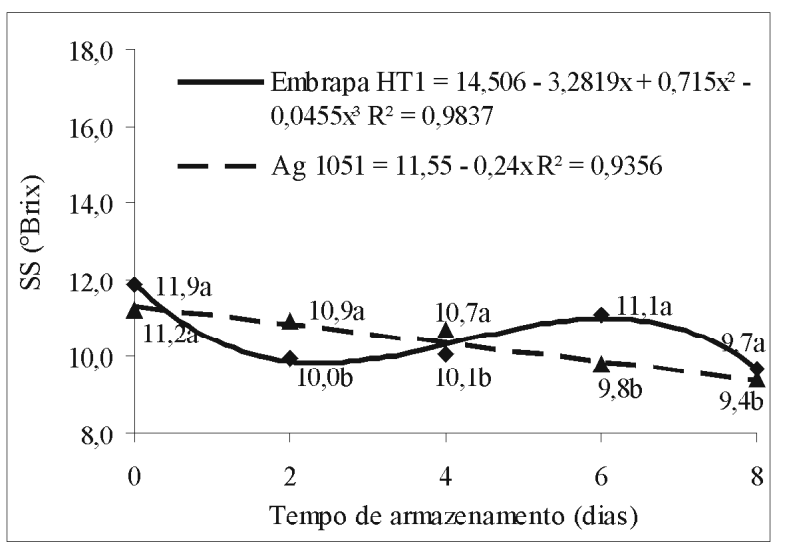

Figura 5 - Estimativa dos teores de sólidos solúveis (SS) de milhos verdes 'Embrapa HT1' e 'Ag 1051' minimamente processados, armazenados sob refrigeração, por 8 dias. *Médias seguidas da mesma letra, em cada tempo, não diferem entre si a 5\% de probabilidade, pelo teste de Tukey.

Os teores de frutose foram maiores para o híbrido Ag 1051, até o $6^{\circ}$ dia de armazenamento, decrescendo ao longo do armazenamento. O teor de frutose no híbrido Embrapa HT1 foi estatisticamente constante, ao longo do armazenamento (Figura 6).

Os teores de frutose apresentaram padrão estatisticamente constante para as temperaturas de $5^{\circ} \mathrm{C}$ e $8^{\circ} \mathrm{C}$, ao longo do armazenamento. No armazenamento a $11^{\circ} \mathrm{C}$, os teores de frutose diminuíram ao longo do armazenamento, apresentando um ligeiro aumento no $8^{\circ}$ dia (Figura 7). 


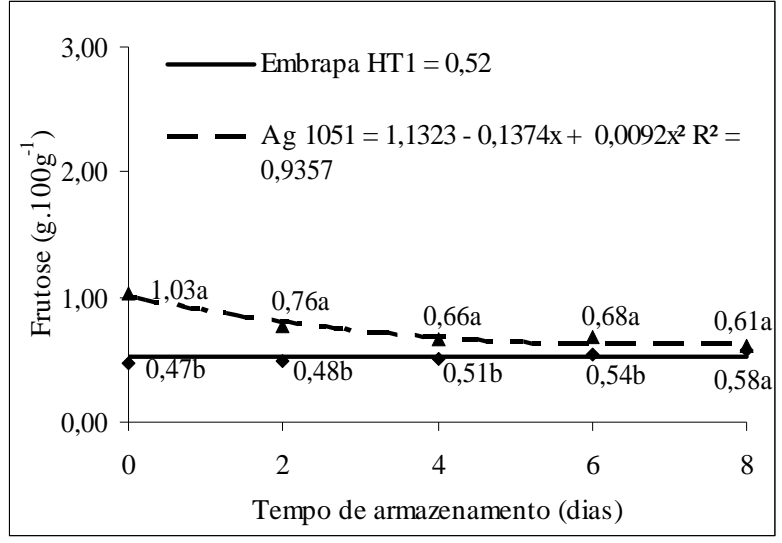

Figura 6 - Estimativa dos teores de frutose $\left(\mathrm{g} .100 \mathrm{~g}^{-1}\right)$ de milhos verdes 'Embrapa HT1' e 'Ag 1051', minimamente processados armazenados sob refrigeração, por 8 dias.

*Médias seguidas da mesma letra, em cada tempo, não diferem entre si a 5\% de probabilidade, pelo teste de Tukey.

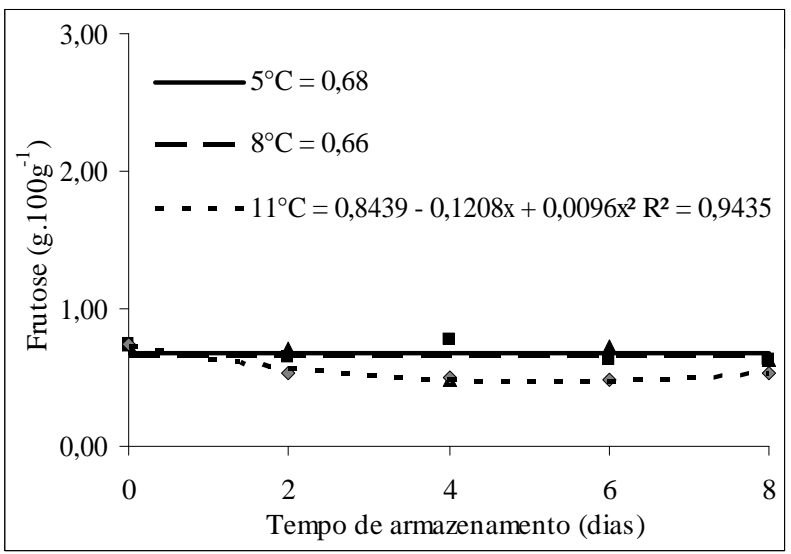

Figura 7 - Estimativa dos teores médios de frutose dos híbridos de milho verde minimamente processados, armazenados em diferentes temperaturas $\left(5^{\circ} \mathrm{C}, 8^{\circ} \mathrm{C}\right.$ e $\left.11^{\circ} \mathrm{C}\right)$, por 8 dias.

Aproximadamente, do primeiro ao sétimo dia de armazenamento o híbrido Ag 1051, armazenado a $5^{\circ} \mathrm{C}$, apresentou teor de glicose superior em relação aos demais tratamentos. Até o $2^{\circ}$ dia de armazenamento, esse mesmo híbrido, em qualquer temperatura de armazenamento, apresentou maiores teores de glicose que o Embrapa HT1. O teor de glicose do híbrido Ag 1051 diminuiu linearmente, ao longo do armazenamento a $5^{\circ} \mathrm{C}$ e, nas demais temperaturas, houve redução até, aproximadamente, o quarto dia, com aumento posterior. Quanto ao híbrido Embrapa HT1, o teor de glicose foi estatisticamente constante nas três temperaturas estudadas ao longo do armazenamento, sendo maior na temperatura de $5^{\circ} \mathrm{C}$ (Figura 8).

As flutuações nos teores de frutose e glicose podem ser atribuídas à variabilidade entre os pontos de colheita das espigas, no momento da colheita. $\mathrm{O}$ decréscimo nos teores de frutose e glicose ao longo do armazenamento pode estar associado ao consumo desses açúcares no processo respiratório e ao seu uso como substrato na síntese de amido.

É importante destacar que, na síntese de amido, no milho verde, ocorre a formação de polissacarídeos solúveis em água (MYERS et al., 2000). Esses são medidos como sólidos solúveis, por isso, os teores de SS são bem maiores que os de açúcares. Hale et al. (2005) e Zhu et al. (1992) encontraram correlações negativas para milho doce entre os valores de SS e açúcares totais.

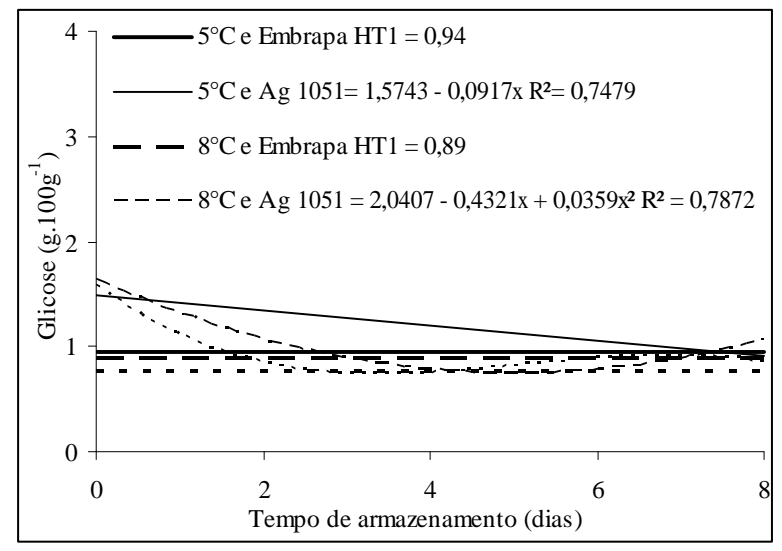

Figura 8 -Estimativa dos teores de glicose de milhos verdes 'Embrapa HT1' e 'Ag 1051' minimamente processados, armazenados em diferentes temperaturas $\left(5^{\circ} \mathrm{C}, 8^{\circ} \mathrm{C}\right.$ e $\left.11^{\circ} \mathrm{C}\right)$, por 8 dias.

O híbrido Embrapa HT1 apresentou maior valor b* $(36,46)$ em relação ao $\mathrm{Ag} 1051(35,49)$. Isso já era de se esperar porque, visualmente, o híbrido de milho verde Embrapa HT1 mostrou amarelo mais intenso que o Ag 1051. $\mathrm{O}$ valor $\mathrm{b}^{*}$ indica variação de coloração do azul ao amarelo, variando entre $-100 \mathrm{a}+70$. Os carotenóides são responsáveis pela coloração amarela do milho (SCOTT \& ELDRIDGE, 2005). Mamede et al. (2006b), estudando os mesmos híbridos de milho verde, encontraram maiores valores de carotenóides totais para o genótipo Embrapa HT1, em comparação ao 'Ag 1051', com valores de 496,14 e $168,19 \mathrm{mg}$ de carotenóides. $100 \mathrm{~g}^{-1}$ de produto fresco, respectivamente. Pode-se inferir, portanto, haver relação direta entre carotenóides e valor $\mathrm{b}^{*}$, o que está de acordo com os resultados encontrados. 
$\mathrm{O}$ valor $\mathrm{L}^{*}$ diminuiu linearmente ao longo do armazenamento de 74,04 para 72,28 (Figura 9), independentemente do híbrido estudado e da temperatura de armazenamento. Deák et al. (1987) também encontraram decréscimo nos valores de $\mathrm{L}^{*}$ para milhos doces armazenados a $10^{\circ} \mathrm{C}$ e $20^{\circ} \mathrm{C}$, por 16 dias. Como o valor $\mathrm{L}^{*}$ é um indicador do escurecimento, houve escurecimento da epiderme dos milhos, durante o armazenamento. Esse escurecimento, não visível a olho nu, pode ter ocorrido pela ação das enzimas polifenoloxidases e peroxidase que estão associadas a modificações na coloração (CHITARRA, 2001).

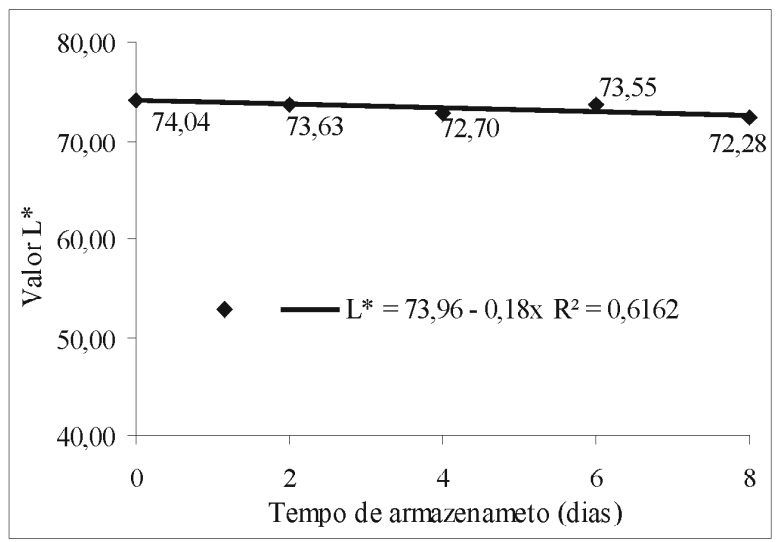

Figura 9 - Estimativa do valor L* dos híbridos de milho verde minimamente processados, armazenados sob refrigeração, por 8 dias.

\section{CONCLUSÃO}

A temperatura de $5^{\circ} \mathrm{C}$ foi a que melhor preservou a qualidade dos híbridos de milho verde do tipo normal minimamente processados estudados, por apresentar perda de massa reduzida e maiores teores de sólidos solúveis, frutose e glicose. O híbrido Ag 1051 pode ser considerado o mais apropriado para o processamento mínimo de milho verde do tipo normal, com base nos resultados de menor perda de massa, maior teor de umidade e frutose.

\section{REFERÊNCIAS BIBLIOGRÁFICAS}

ASSOCIATION OF OFFICIAL AGRICULTURAL CHEMISTS. Official methods of the Association of the Agricultural Chemists. 15. ed. Washington, DC, 2000. 2 v.

BURNS, J. L. Lightly processed fruits and vegetables: introduction to the colloquium. HortScience, Amsterdam, v. 30, n. 1, p. 14-17, 1995.
CHITARRA, M. I. F. Processamento mínimo de frutas e hortaliças. Lavras: UFLA/FAEPE, 2000. 113 p. Apostila.

CHITARRA, M. I. F. Alimentos minimamente processados. Lavras: UFLA/FAEPE, 2001. 93 p. (Textos acadêmicos).

CHITARRA, M. I. F.; CHITARRA, A. B. Pós-colheita de frutos e hortaliças: fisiologia e manuseio. 2. ed. rev. e ampl. Lavras: UFLA, 2005. 249 p.

CAMACHO, C. et al. Estudio de la estabilidad de las características químicas, microbiológicas y sensoriales de mazorcas refrigeradas de híbridos de maíz super dulce. Archivos Latinoamaricanos de Nutrición, Caracas, v. 51, n. 2, p. 180-186, 2001.

DEÁK, T. et al. Extending the shelf life of fresh sweet corn by shrink-wrapping, refrigeration, and irradiation. Journal of Food Science, Chicago, v. 52, n. 6, p. 1625-1631, Nov. 1987.

FERREIRA, D. F. Análises estatísticas por meio do SISVAR para windows versão 4.0. In: REUNIÃO ANUAL DA REGIÃO BRASILEIRA DA SOCIEDADE INTERNACIONAL DE BIOMETRIA, 45., 2000, São Carlos. Resumos... São Carlos: UFSCar, 2000. p. 235.

HALE, T. A.; HASSELL, R. L.; PHILLIPS, T. Refractometer measurements of soluble solid concentration do not reliably predict sugar content in sweet corn. HortTechnology, Alexandria, v. 15, n. 3, p. 668-672, July/ Sept. 2005.

INTERNATIONAL ORGANIZATION FOR STANDARDIZATION. ISO 2173: fruit and vegetable products: determination of soluble solids content: refractometric method. Genève, 1978.

KADER, A. A. Postharvest biology and technology: an overview. In: Postharvest technology of horticultural crops. 3. ed. Oakland: University of Califonia, 2002. cap. 4, p. 39-47. (Publication, 3311).

LUENGO, R. F. A. Armazenamento refrigerado. In: LUENGO, R. F. A.; CALBO, A. G. (Eds.). Armazenamento de hortaliças. Brasília, DF: Embrapa Hortaliças, 2001. p. 60-65.

LUENGO, R. F. A.; CALBO, A. G. Armazenamento de hortaliças. Brasília, DF: Embrapa Hortaliças, 2001. p. 201-203. 
MACRAE, R. Food science and technology: a series of monoghraphys: HPLC in food analysis. 2. ed. New York: Academic, 1998.

MAMEDE, A. M. G. N. et al. Determinação da textura de grãos de milho verde minimamente processado. In: ENCONTRO NACIONAL SOBRE PROCESSAMENTO MÍNIMO DE FRUTAS E HORTALIÇAS, 4.; SIMPÓSIO IBERO-AMERICANO DE VEGETAIS FRESCOS CORTADOS, 1., 2006, São Pedro. Resumos... São Pedro, 2006a. p. 192-192.

MAMEDE, A. M. G. N. et al. Efeito da saponificação na extração dos carotenóides em milho verde minimamente processado. In: CONGRESSO BRASILEIRO DE CIÊNCIA E TECNOLOGIA DE ALIMENTOS, 10., 2006, Curitiba. Anais... Curitiba: SBCTA, 2006b. p. 1185.

MARCOS, S. K. et al. Influência do resfriamento do ambiente de armazenamento e da embalagem sobre o comportamento pós-colheita do milho verde. Revista Brasileira de Engenharia Agrícola e Ambiental, Campina Grande, v. 3, n. 1, p. 41-44, 1999.

MYERS, A. M. Recent progress toward understanding biosynthesis of the amylopectin crystal. Plant Physiology, Washington, v. 122, p. 989-997, Apr. 2000.

NUNES, M. C. do N.; EMOND, J. P. Storage temperature. In: BARTZ, J. A.; BRECHT, J. K. (Eds.). Postharvest physiology and pathology of vegetables. New York: M. Dekker, 2003. cap. 8, p. 209-228.

PAES, M. C. D.; MODESTA, R. C. D.; GAMA, E. E. G. Textura em grãos de híbridos experimentais destinados à produção de milho verde. In: CONGRESSO NACIONAL DE MILHO E SORGO, 25., 2004, Cuiabá. Anais... Cuibá, 2004. p. 513.

PEREIRA FILHO, I. A.; CRUZ, J. C.; GAMA, E. E. G. Cultivares de milho para o consumo verde. In: PEREIRA FILHO, I. A. (Ed.). O cultivo do milho verde. Brasília, DF: Embrapa Informação Tecnológica, 2003. cap. 1, p. 17-30.

SCHLIMME, D. V. Marketing lightly processed fruit and vegetables. Hortscience, Alexandria, v. 30, n. 1, p. 15-17, Feb. 1995

SCOTT, C. E.; ELDRIDGE, A. L. Comparison of carotenoid content in fresh, frozen and canned corn. Journal of Food Composition and Analysis, San Diego, v. 18, p. 551-559, 2005.

ZHU, S.; MOUNT, J. R.; COLLINS, J. L. Sugar and soluble solids changes in refrigerated sweet corn (Zea mays L). Journal of Food Science, Chicago, v. 57, n. 2, p. 454-457, Mar. 1992. 